\title{
Associations between neurological soft signs, chronotype and sleep quality in schizophrenia
}

\author{
Esin Evren Kilicaslan ${ }^{1}$, Merve Atilgan $^{1 \oplus}$, Mustafa Kurt ${ }^{1 \oplus}$, Murat Boysan ${ }^{2}{ }^{\circledR}$ Mustafa Gulec $^{1}$ \\ ${ }^{1}$ Izmir Katip Celebi University, Ataturk Training and Research Hospital, Department of Psychiatry, Izmir - Turkey \\ ${ }^{2}$ Ankara Social Sciences University, Faculty of Social Sciences and Humanities, Department of Psychology, Ankara - Turkey
}

\begin{abstract}
Objective: Neurological soft signs (NSS) and sleep disorders are quite common in schizophrenia. Both symptom clusters have been proposed as candidate endophenotypes for the disorder. This study aimed to investigate the relationships between NSS, chronotype and sleep quality among patients with schizophrenia.

Method: Positive and Negative Syndrome Scale, The Neurological Evaluation Scale (NES), Morningness-Eveningness Questionnaire (MEQ), Pittsburgh Sleep Quality Index (PSQI), Beck Depression Inventory (BDI), and Beck Anxiety Inventory (BAI) were administered to 50 patients with schizophrenia and 50 age- and gender-matched healthy control participants. Group differences were assessed using multivariate covariance models. We used stepwise multiple regression analysis to evaluate the potential relationships between NSS and clinical characteristics, diurnal preferences, sleep quality, anxiety, and depression in patients with schizophrenia.

Results: Patients with schizophrenia were more likely to reveal severe impairments in NSS than healthy control participants even after controlling for demographic characteristics and the MEQ, PSQI, BAI, and BDI scores. In addition, patients were more prone to report evening-type characteristics than healthy individuals. Sleep disturbances were significant correlates of deficits in total NES, motor coordination, and other NSS. PSQI global and poor habitual sleep efficiency were associated with sequencing of complex motor acts. No relationships were found between NSS and chronotype. However, general psychopathology significantly contributed to NSS.
\end{abstract}

Conclusion: The data showed that evening-type diurnal preferences and sleep quality as well as NSS seem to have complex implications in schizophrenia.

Keywords: Chronotype, neurological soft signs, schizophrenia, sleep quality

\section{INTRODUCTION}

Neurological soft signs (NSS) are minor abnormal signs on clinical neurological examination that are mostly concentrated in the areas of sensory integrity, motor coordination, and sequential motor actions (1-3). Collectively, they may suggest the existence of an organic pathology (4).
In almost all studies, NSS were found to be significantly higher in patients with schizophrenia than in control participants (5). Moreover, NSS have been shown to be more common in first-degree relatives of patients with schizophrenia than control participants $(6,7)$. According to previous studies, the presence of a high rate of NSS in schizophrenia patients is associated with early neurodevelopmental abnormalities $(8,9)$ and

How to cite this article: Evren Kilicaslan E, Atilgan M, Kurt M, Boysan M, Gulec M. Associations between neurological soft signs, chronotype and sleep quality in schizophrenia. Dusunen Adam The Journal of Psychiatry and Neurological Sciences 2020;33:270-280.

Correspondence: Esin Evren Kilicaslan, Izmir Katip Celebi University, Ataturk Training and Research Hospital, Department of Psychiatry, Izmir - Turkey E-mail: esiniyidogan@gmail.com

Received: April 16, 2020; Revised: May 24, 2020; Accepted: July 01, 2020 
is not associated with prognosis or treatment (10). However, NSS do not show the same homogeneity in all schizophrenia patient groups. In patients with negative symptoms, chronic progression, resistance to treatment, and impaired cognitive functions, NSS were found to be more common than other patients (11-13). NSS are, therefore, an endophenotype candidate that can be used for research on the genetic origin of schizophrenia.

In humans, the sleep-wake cycle, body temperature, hormone levels, affect, and certain cognitive functions have a daily rhythm called circadian rhythm $(14,15)$. Advance, delay, or deterioration in the circadian rhythm is strongly associated with psychiatric disorders, particularly, mood disorders, such as bipolar depression, major depression, and seasonal affective disorders (16). Humans have different chronotypes called morningness and eveningness in terms of differences in biological and behavioral rhythms, including sleep-wake cycles, body temperature fluctuation, cortisol release, and melatonin release time. Morningness-type individuals go to sleep early, wake up early, and perform better in the morning. Eveningness-type individuals go to sleep late and prefer evening hours for activities $(17,18)$. There is a phase difference of about $2 \mathrm{~h}$ between the two types. This phase difference is also approximately $2 \mathrm{~h}$ in terms of the periods of release of hormones, such as body temperature hormones, cortisol, and melatonin (18). In addition,a relationship between depression and chronotypes due to circadian rhythm differences has beendefined. While being an evening-typeindividual is considered a risk for the development of depression in healthy individuals (19), eveningness-type depressive patients have more suicidal ideation and higher depression scores and lower sleep quality than morningness-type depressive patients $(20,21)$. Features such as neuroticism, impulsivity, stressful lifestyle, and sleep disturbances (i.e., irregular sleep-wake cycles, decreased sleep activity, and decreased slow-wave sleep) are associated with circadian rhythm in the relationship between eveningness and depression (21-23). Unlike morningness-type individuals, eveningness-type individuals have a delayed phase, incompatible internal and external rhythm determinants, and, thus, a disturbed relationship between circadian rhythm and homeostasis (24).

Schizophrenia has long been associated with sleep abnormalities; however, only a few studies have been conducted on circadian rhythms and chronotypes (25). These studies indicated that patients with schizophrenia have severe circadian sleep-wake disturbances, and schizophrenia may be associated with the eveningness chronotype (26-28). A complex interaction of wake and sleep mechanisms, neurotransmitter systems, multiple brain regions, and modulatory hormones is thought to be responsible for the generation of sleep and circadian rhythm disturbances in patients with schizophrenia $(26,29)$. Variations in multiple genes have been shown to be associated with rhythm-related sleep disorders, sleep homeostasis, phenotypic differences between morning and evening preferences (30), midbrain dopamine regulation, and reward processing (31). These findings suggest that sleep-wake disturbances in patients with schizophrenia may have a genetic basis (32). The demonstration that circadian rhythm disorders predict poor prognosis at a 1-year follow-up in adolescents at clinically high risk for psychosis (33) and a strong association between circadian rhythm integrity and cognitive performance (34) also support that sleep-wake disturbances in patients with schizophrenia may provide an endophenotypic dimension.

Concerning both NSS and chronotype in schizophrenia, the presence of common features, such as those observed before onset of the disease, thoserelated to cognitive impairment, and those providing evidence of a genetic basis, suggest that these dimensions may be related. In this study, we aimed to investigate NSS and chronotype and to examine the comparative relationship between these variables in patients with schizophrenia and healthy control participants. We explored whether NSS was significantly associated with diurnal preferences and sleep quality. We investigated whether schizophrenia patients differenced in their NSS symptoms from health controls after adjusting for diurnal preferences, sleep quality, anxiety, depression, and demographics. We also investigated group differences in diurnal preferences and sleep quality after controlling for demographic characteristics. Finally, we identified the predictive values of demographic and clinical variables, diurnal preferences, sleep quality, anxiety, and depression on NSS.

\section{METHOD}

\section{Participants}

Fifty outpatients who had consecutively applied to the Izmir Katip Celebi University Education and Research Hospital, Psychiatry Outpatient Clinic within the specified 20 days and met the inclusion criteria were included in the study. Patients with clinically significant and/or considerable depressive symptoms and patients 
with severe cognitive impairment were excluded from the study. Outpatients were preferred because hospitalization was thought to adversely affect sleep patterns and comparison with healthy control participants. All patients were taking antipsychotics. The patients who used antiparkinsonian medications, benzodiazepines, antihistaminic medications, minor tranquilizers, and other psychotropics and patients who had extrapyramidal side effects were excluded because all these factors were thought to affect NSS. Fifty healthy age- and gender-matched controls were used forstatistical analysis (Table 1). The mean age of the patients and healthy control participants was 37.73 years [standard deviation (SD)12.42, range 20-67].

All participants gave written and informed consent to participate in accordance with the Declaration of Helsinki after the institutional review board approval. The study was approved by the local ethics committee.

\section{Measures}

Two examiners who were also qualified psychiatrists confirmed the diagnoses using the fourth edition of "Structural Clinical Interview for the Diagnostic and Statistical Manual of Mental Disorders" (SCID-IV) (35).

Neurological Evaluation Scale (NES): We assessed NSS with the NES. The NES scale yields a total and four neurological subscale scores of sensory integration, motor coordination, sequencing of complex motor acts, and other NSS" (36). The Turkish version of the NES had adequate reliability and validity (37).

Positive and Negative Syndrome Scale (PANSS): The PANSS was used to evaluate the psychotic symptoms, which contains three subscales ofpositive, negative, and general psychopathology. The PANNS consists of 30 items (38). The Turkish version of the PANNS was demonstrated to have good psychometric properties (39).

Morningness-Eveningness Questionnaire (MEQ): Chronotype was evaluated by using the MEQ (40). The MEQ is a self-assessment questionnaire that measures the peak and nadir of one's day-to-day activities. Horne and Ostberg confirmed this scale against daily temperature rhythms. The Turkish MEQ had good reliability and reliability (41).

Pittsburgh Sleep Quality Index (PSQI): The PSQI was used to assess quality of sleep among participants (42). This PSQI contains 19 items examining seven components of subjective sleep quality, habitual sleep efficiency, sleep latency, sleep disturbances, sleep duration, use of sleeping medication, and daytime dysfunction. The validity and reliability of the Turkish PSQI was demonstrated by Agargun et al. (43).
Beck Depression Inventory (BDI): Examination of depressive symptoms was based on the BDI. BDI is a 21-item self-report instrument designed to evaluate the presence and severity of symptoms of depression. Each item is asked to be rated on a 4-point scale, ranging from 0 and 3. A total score is obtained by summing up the item responses, yielding a total score ranging from 0 to 63 (44). The BDI was translated into Turkish, and good validity and reliability was reported for the Turkish version (45).

Beck Anxiety Inventory (BAI): The BAI was devised to examine anxiety arousal symptomsover the past week. Participants are asked to rate each item on a 4 -point scale, ranging from 0 and 3 . The greater the scores, the higher the symptom severity. The BAI is the gold standard in evaluating physiological anxious arousal (46). The BAI was translated into Turkish, and good validity and reliability was reported for the Turkish version (47).

\section{Statistical Analysis}

We began with computing descriptive statistics for sociodemographic and clinical features of the patients and healthy controls. Using nonparametric $\chi$-squared test, we compared gender and marital status between groups. We used independent sample t-test in order to compare age and duration of education between patients with psychosis and healthy controls. We performed Pearson product moment correlation coefficients of total and subscale scores on the NES with psychological variables.

Using general linear modeling approach, we assessed group differences in NSS, diurnal preferences and sleep quality. For the total scores of the NES, we used analysis of covariance (ANCOVA) after controlling for age, gender, marital status, education (yrs), and scores on the BAI, BDI, MEQ, and PSQI to compare groups. Next, to explore significance of multivariate variation on NSS between groups, we carried out multivariate analysis of covariance (MANCOVA) for the four subscales of the NES (sensory integration, motor coordination, sequencing of complex motor acts, and other NSS) after controlling for age, gender, marital status, education (yrs), and scores on the BAI, BDI, MEQ, and PSQI. Then, each subscale of the NES was compared between groups using ANCOVA.

A body of evidence has well-documented in the literature that depression and anxiety have substantial shared variances with diurnal preferences and sleep quality (48-51). Therefore, we carried out two ANCOVAs after adjusting for only demographic variables (age, gender, marital status, education), in 
which the MEQ and PSQI total scores were dependent variables. Next, seven components of the PSQI (subjective sleep quality, sleep latency, sleep duration, habitual sleep efficiency, sleep disturbances, use of sleeping medication and daytime dysfunction) were subjected to MANCOVA together after controlling for demographics. Finally, group difference for each component of the PSQI was evaluated using ANCOVA.

We carried out four stepwise multiple regression analyses among patients with schizophrenia. The total and subscale scores on the NES were dependent variables in theregression analyses. Socio-demographic variables (age, gender, education, and marital status), clinical features (age at the onset, duration of the illness (yrs), and number of hospitalization), subscale scores of the PANSS (positive and negative symptom severity, and general psychopathology), the PSQI components (subjective sleep quality, habitual sleep efficiency, sleep latency, sleep disturbances, sleep duration, use of sleeping medication, and daytime dysfunction), and total scores on the MEQ, BAI and BDI regressed onto neurological symptoms as measured by total and subscales the NES.

\section{RESULTS}

The sociodemographic and clinical characteristics of the patients and healthy control participants are presented in Table 1 . Gender $(\chi[1]=361, \mathrm{p}=0.548)$ and age $(\mathrm{t}[98]=0.377, \mathrm{p}=0.707)$ did not statistically significantly differ between schizophrenia patients and healthy control participants. Patients with schizophrenia were more likely to be single than healthy control participants $(\chi[1]=9.180, \mathrm{p}=0.002)$.
Using Pearson product moments correlation coefficients, we evaluated the associations between scale scores and NSS by groups. Schizophrenia patients with high NSS as indexed by the NES reported significantly greater scores of general psychopathology $(r=0.28$, $\mathrm{p}<0.05)$. Impairment in sensory integration was significantly correlated with general psychopathology $(\mathrm{r}=0.28, \mathrm{p}<0.05)$, poor subjective sleep quality $(\mathrm{r}=0.30$, $\mathrm{p}<0.05)$, and longer sleep latency $(\mathrm{r}=0.30, \mathrm{p}<0.05)$ among patients with schizophrenia. In the healthy control group, anxiety $(\mathrm{r}=0.33 \mathrm{p}<0.05)$, depression $(\mathrm{r}=0.33, \mathrm{p}<0.05)$, and sleep disturbance $(\mathrm{r}=0.41, \mathrm{p}<0.01)$ were significantly correlated with the total NES score. Difficulties in motor coordination were significantly associated with sleep disturbances $(\mathrm{r}=0.55, \mathrm{p}<0.01)$. Deterioration in the sequencing of complex motor acts was significantly correlated with anxiety $(\mathrm{r}=0.48$, $\mathrm{p}<0.01)$, depression $(\mathrm{r}=0.45, \mathrm{p}<0.01)$, poor sleep quality $(\mathrm{r}=0.34, \mathrm{p}<0.05)$, and disturbance in habitual sleep efficiency $(\mathrm{r}=0.33, \mathrm{p}<0.05)$ among control participants. Anxiety $(\mathrm{r}=0.31, \mathrm{p}<0.05)$, depression $(\mathrm{r}=0.31, \mathrm{p}<0.05)$, and sleep disturbances $(\mathrm{r}=0.40, \mathrm{p}<0.01)$ were significantly correlated with other NSS in healthy participants. These findings are presented in Table 2.

To explore the individual differences on scale scores between the patients and healthy control participants, we conducted a series of general linear analyses. First, we conducted an ANCOVA between patients and healthy control participants, in which the unique variance of dependent variables of the NES total scores were controlled for sociodemographic variables (i.e., age, gender, marital status, and education) and the total BAI, BDI, MEQ, and PSQI scores. Patients demonstrated significantly greater total NES scores than the control

Table 1: Socio-demographic and clinical characteristics of the patients and healthy controls

Patients $(n=50)$

Controls $(\mathbf{n}=\mathbf{5 0})$

\begin{tabular}{|c|c|c|c|c|c|}
\hline \multicolumn{6}{|l|}{ Gender } \\
\hline Female $n,(\%)$ & 25 & $50 \%$ & 28 & $56 \%$ & $\chi(1)=361 p=0.548$ \\
\hline Male n, (\%) & 25 & $50 \%$ & 22 & $44 \%$ & \\
\hline \multicolumn{6}{|l|}{ Marital status } \\
\hline Single $n,(\%)$ & 36 & $72 \%$ & 21 & $42 \%$ & $\chi(1)=9.180 \mathrm{p}=0.002$ \\
\hline Married n, (\%) & 14 & $28 \%$ & 29 & $58 \%$ & \\
\hline Age (Mean, SD) & 37.26 & 10.98 & 38.20 & 13.80 & $t(98)=0.377 p=0.707$ \\
\hline Education (yrs) (Mean, SD) & 9.62 & 4.36 & 14.10 & 3.82 & $t(98)=5.469 p<0.001$ \\
\hline Age at the onset (Mean, SD) & 26.00 & 10.66 & - & - & \\
\hline Duration of illness (Mean, SD) & 11.26 & 7.96 & - & - & \\
\hline Number of hospitalizations (Mean, SD) & 2.46 & 2.70 & - & - & \\
\hline Age at first hospitalization (Mean, SD) & 30.18 & 12.03 & - & - & \\
\hline
\end{tabular}


Table 2: Pearson product-moment correlation coefficients

\begin{tabular}{|c|c|c|c|c|c|}
\hline & $\begin{array}{c}\text { Neurological } \\
\text { Evaluation } \\
\text { Scale }\end{array}$ & $\begin{array}{c}\text { Sensory } \\
\text { Integration }\end{array}$ & $\begin{array}{c}\text { Motor } \\
\text { Coordination }\end{array}$ & $\begin{array}{l}\text { Sequencing } \\
\text { of Complex } \\
\text { Motor Acts }\end{array}$ & Others \\
\hline Positive symptoms & $0.19 /-$ & $0.19 /-$ & $0.21 /-$ & $0.13 /-$ & $0.13 /-$ \\
\hline Negative symptoms & $0.23 /-$ & $0.26 /-$ & $0.11 /-$ & $0.13 /-$ & $0.20 /-$ \\
\hline General psychopathology & $0.28 * /-$ & $0.28 * /-$ & $0.09 /-$ & $0.19 /-$ & $0.27 /-$ \\
\hline Beck Anxiety Inventory & $0.18 / 0.33^{*}$ & $0.16 /-0.19$ & $0.16 / 0.14$ & $0.21 / 0.48^{* *}$ & $0.08 / 0.31^{*}$ \\
\hline Beck Depression Inventory & $0.19 / 0.36^{*}$ & $0.25 /-0.06$ & $0.22 / 0.20$ & $0.10 / 0.45^{* *}$ & $0.12 / 0.31^{*}$ \\
\hline Morningness Eveningness Questionnaire & $-0.15 / 0.08$ & $-0.18 /-0.01$ & $-0.10 / 0.23$ & $-0.13 /-0.04$ & $-0.10 / 0.13$ \\
\hline Pittsburgh Sleep Quality Index & $0.18 / 0.25$ & $0.24 / 0.14$ & $0.27 / 0.09$ & $0.15 / 0.34^{*}$ & $0.06 / 0.14$ \\
\hline Subjective Sleep Quality & $0.14 / 0.19$ & $0.30 * / 0.21$ & $0.19 /-0.06$ & $0.15 / 0.24$ & $-0.02 / 0.10$ \\
\hline Sleep latency & $0.24 / 0.06$ & $0.30 * / 0.02$ & $0.17 /-0.15$ & $0.14 / 0.16$ & $0.18 / 0.03$ \\
\hline Sleep duration & $0.06 / 0.01$ & $0.26 / 0.19$ & $0.12 / 0.01$ & $0.01 / 0.01$ & $-0.05 /-0.07$ \\
\hline Habitual sleep efficiency & $0.13 / 0.19$ & $0.24 / 0.10$ & $0.16 /-0.02$ & $0.06 / 0.33^{*}$ & $0.06 / 0.08$ \\
\hline Sleep disturbances & $0.18 / 0.41^{* *}$ & $0.16 / 0.05$ & $0.03 / 0.55^{* *}$ & $0.26 / 0.26$ & $0.10 / 0.40^{* *}$ \\
\hline Use of sleeping medication & $-0.02 / 0.09$ & $-0.16 /-0.02$ & $0.19 /-0.15$ & $0.11 / 0.22$ & $-0.08 / 0.05$ \\
\hline Daytime dysfunction & $0.10 / 0.16$ & $0.08 / 0.04$ & $0.18 / 0.27$ & $-0.05 / 0.17$ & $0.12 / 0.08$ \\
\hline
\end{tabular}

${ }^{*}: p<0.05 ;{ }^{* *}: p<0.01$. Correlation analyses conducted in the patient group is presented in the left side of the columns and analyses conducted in control group are presented in the right side of the columns

participants $\left(\mathrm{F}[1,90]=15.312, \mathrm{p}<0.001, \eta^{2}=0.145\right)$. Next, we conducted a MANCOVA, in which differences between the patient group and control group in the four subscales of the NES (sensory integration, motor coordination, sequencing of complex motor acts, and other NSS) were assessed after controlling for sociodemographic variables and the total BAI, BDI, MEQ, and PSQI scores. The MANCOVA yielded a significant Wilk's $\lambda$ value of 0.812 (F $[4,87]=5.043$, $\left.\mathrm{p}=0.01, \eta^{2}=0.188\right)$. Therefore, to explore the group differences between patients and healthy controls on each subscale of the NES, we carried out four ANCOVAs. Each subscale of the NES (sensory integration, motor coordination, sequencing of complex motor acts, and other NSS) was subjected to ANCOVA separately. Compared to control participants, schizophrenia patients had marked deficits in sensory integration $\left(\mathrm{F}[1,90]=14.484, \mathrm{p}<0.001, \eta^{2}=0.139\right)$, motor coordination $\left(\mathrm{F}[1,90]=4.105, \mathrm{p}<0.05, \eta^{2}=0.044\right)$, the sequencing of complex motor acts $(\mathrm{F}[1,90]=11.288$, $\left.\mathrm{p}<0.01, \eta^{2}=0.111\right)$, and other NSS $(\mathrm{F}[1,90]=8.657$, $\left.\mathrm{p}<0.01, \quad \eta^{2}=0.088\right)$, even after adjusting for sociodemographic characteristics (age, gender, marital status, and education) and other scale scores (BAI, BDI, MEQ, and PSQI). Findings are presented in Table 3.

We conducted an ANCOVA between the groups for the total MEQ scores after adjusting for sociodemographic features(age, gender, marital status, and education). ANCOVA showed that schizophrenia patients were more prone to evening-type diurnal preferences than healthy participants $(\mathrm{F}[1,94]=6.694$, $\left.\mathrm{p}<0.05, \eta^{2}=0.066\right)$. In a similar vein, we conducted another ANCOVA between the groups for the PSQI global scores after controlling for sociodemographic

Table 3: Group differences in neurological soft signs between patients and healthy controls $(n=100)^{\ddagger}$

\begin{tabular}{|c|c|c|c|c|c|c|c|c|}
\hline & \multicolumn{2}{|c|}{ Patients $(n=50)$} & \multicolumn{2}{|c|}{ Controls $(n=50)$} & \multirow[b]{2}{*}{ df } & \multirow[b]{2}{*}{$\mathbf{F}$} & \multirow[b]{2}{*}{$\mathbf{p}$} & \multirow[b]{2}{*}{$n^{2}$} \\
\hline & Mean & SD & Mean & SD & & & & \\
\hline Neurological Evaluation Scale & 10.54 & 7.30 & 2.60 & 2.84 & $(1,90)$ & 15.312 & $<0.001$ & 0.145 \\
\hline Sensory integration & 1.96 & 1.71 & 0.22 & 0.62 & $(1,90)$ & 14.484 & $<0.001$ & 0.139 \\
\hline Motor coordination & 0.82 & 1.17 & 0.16 & 0.42 & $(1,90)$ & 4.105 & 0.046 & 0.044 \\
\hline Sequencing of complex motor acts & 3.18 & 2.29 & 0.92 & 1.16 & $(1,90)$ & 11.288 & 0.001 & 0.111 \\
\hline Other neurological soft signs & 4.58 & 3.93 & 1.30 & 1.49 & $(1,90)$ & 8.657 & 0.004 & 0.088 \\
\hline
\end{tabular}

${ }^{\ddagger}$ Analysis of covariance was conducted after controlling for age, gender, marital status, education (yrs), and scores on the Beck Anxiety Inventory, Beck Depression Inventory, Morningness-Eveningness Questionnaire, and Pittsburgh Sleep Quality Index. SD: Standard deviation 
features (age, gender, marital status, and education). The ANCOVA analysis result with the PSQI total score as the dependent variable was not statistically significant ( $\left.F[1,94]=0.118, p=0.732, \eta^{2}=0.001\right)$. Then, we carried out a MANCOVA between groups in which the PSQI subscales were treated as the dependent variables set. MANCOVA between the patient and control groups with the seven components of the PSQI as the dependent variables revealed significant multivariate group difference (Wilk's $\lambda=0.815, F[7,88]=5.002 \mathrm{p}=0.010$, $\left.\eta^{2}=0.185\right)$. Therefore, we carried out seven ANCOVAs to explore the differences in the PSQI components between patients and healthy controls. The ANOVA for use of sleep medication subscale revealed that patients were more likely to use sleep medications than control participants ( $\left.\mathrm{F}[1,94]=10.649, \mathrm{p}<0.01, \eta^{2}=0.102\right)$. However, group differences in subjective sleep quality $\left(\mathrm{F}[1,94]=3.751, \mathrm{p}=0.056, \eta^{2}=0.038\right)$, sleep latency $(\mathrm{F}[1$, $\left.94]=0.522, \mathrm{p}=0.472, \eta^{2}=0.006\right)$,sleep duration ( $\mathrm{F}[1$, 94] $\left.=1.284, p=0.260, \eta^{2}=0.013\right)$, habitual sleep efficiency ( $\left.F[1,94]=0.161, p=0.689, \eta^{2}=0.002\right)$, sleep disturbances ( $\left.F[1,94]=1.009, \mathrm{p}=0.318, \eta^{2}=0.011\right)$, and daytime dysfunction $\left(F[1,94]=0.522, \mathrm{p}=0.472, \eta^{2}=0.006\right)$ were not significant. These findings are presented in Table 4.

Using stepwise multiple regression analysis in the patient group $(n=50)$, we investigated the predictive value of positive symptoms, negative symptoms, general psychopathology, diurnal preferences, anxiety, depression, the seven components of the PSQI, and sociodemographic (i.e., age, gender, marital status and levels of education) and clinical features (i.e., duration of the illness and number of hospitalizations) on the total and subscale NES scoresseperately. To this end, we run five multiple stepwise regression analyses.In the first regression analysis, in which the total NES score was the dependent variable, the final model converged at the second step. Increased levels of general psychopathology $(\beta=0.30, t=2.205, p<0.05)$ and lower levels of education $(\beta=-0.274, t=-2.041, p<0.05)$ were significantly related to NSS, explaining $15.5 \%$ of the variance in the total NES scores. The second multiple regression model converged at the first step that being male $(\beta=0.40, t=3.031, p<0.01)$ was significantly associated with impairment in sensory integration. The third stepwise multiple regression analysis showed that the number of hospitalizations $(\beta=0.40, t=2.975$, $\mathrm{p}<0.01)$ was significantly associated with impairment in motor coordination. In the fourth stepwise regression analysis, we identified that patients with lower levels of education $(\beta=-0.42, t=-3.247, p<0.01)$ reported significant deterioration in the sequencing of complex motor acts. In the final stepwise regression analysis, we found that neither of the independent variables significantly contributed to other soft neurological signs. The results of these analyses are presented in Table 5.

\section{DISCUSSION}

The most salient finding of this study was that NSS was prominent among schizophrenia patients in comparison to controls after controlling for anxiety, depression, sleep quality, diurnal preferences and sleep quality as well as demographic features. Evening-type diurnal preferences were more likely among psychotic patients than controls. Even though group differences were not significant, sleep disturbance was tied to the NES total and motor coordination deficits among patients. Sequencing of complex motor acts was a substantial correlate of the PSQI global and poor habitual sleep efficiency. General psychopathology was predictive of NSS.

Table 4: Group differences in diurnal preferences and sleep quality between patients and healthy controls ( $n=100)^{*}$

\begin{tabular}{|c|c|c|c|c|c|c|c|c|}
\hline & \multicolumn{2}{|c|}{ Patients $(n=50)$} & \multicolumn{2}{|c|}{ Controls $(n=50)$} & \multirow[b]{2}{*}{ df } & \multirow[b]{2}{*}{$\mathbf{F}$} & \multirow[b]{2}{*}{$\mathbf{p}$} & \multirow[b]{2}{*}{$\eta 2$} \\
\hline & Mean & SD & Mean & SD & & & & \\
\hline Morningness-Eveningness Questionnaire & 55.86 & 6.08 & 51.94 & 10.38 & $(1,94)$ & 6.694 & 0.011 & 0.066 \\
\hline Pittsburgh Sleep Quality Index & 7.00 & 4.06 & 5.70 & 3.35 & $(1,94)$ & 0.118 & 0.732 & 0.001 \\
\hline Subjective Sleep Quality & 1.00 & 0.99 & 1.10 & 0.61 & $(1,94)$ & 3.751 & 0.056 & 0.038 \\
\hline Sleep latency & 1.20 & 0.88 & 0.96 & 0.86 & $(1,94)$ & 0.522 & 0.472 & 0.006 \\
\hline Sleep duration & 0.44 & 0.86 & 0.60 & 0.93 & $(1,94)$ & 1.284 & 0.260 & 0.013 \\
\hline Habitual sleep efficiency & 0.68 & 1.02 & 0.56 & 0.97 & $(1,94)$ & 0.161 & 0.689 & 0.002 \\
\hline Sleep disturbances & 1.46 & 0.58 & 1.18 & 0.66 & $(1,94)$ & 1.009 & 0.318 & 0.011 \\
\hline Use of sleeping medication & 1.32 & 1.42 & 0.32 & 0.82 & $(1,94)$ & 10.649 & 0.002 & 0.102 \\
\hline Daytime dysfunction & 0.90 & 0.97 & 0.98 & 0.94 & $(1,94)$ & 0.522 & 0.472 & 0.006 \\
\hline
\end{tabular}

${ }^{*}$ Analysis of covariance was conducted after controlling for age, gender, marital status and education (yrs), SD: Standard deviation 
Table 5: Stepwise multiple regression analysis on neurological soft signs in patient group ( $n=50)$

\begin{tabular}{|c|c|c|c|c|c|c|}
\hline Dependent variable & $\mathbf{R}^{2}$ & Independent variable & Model F test & B & $\mathbf{t}$ & $\mathbf{p}$ \\
\hline \multicolumn{7}{|c|}{ Neurological Evaluation Scale } \\
\hline Step 1 & 0.080 & $\begin{array}{c}\text { General } \\
\text { psychopathology }\end{array}$ & $F(1,48)=4.196, p=0.046$ & 0.284 & 2.048 & 0.046 \\
\hline \multirow[t]{2}{*}{ Step 2} & 0.155 & $\begin{array}{c}\text { General } \\
\text { psychopathology }\end{array}$ & $F(2,47)=4.318, p=0.019$ & 0.296 & 2.205 & 0.032 \\
\hline & & Education (yrs) & & -0.274 & -2.041 & 0.047 \\
\hline \multicolumn{7}{|l|}{ Sensory integration } \\
\hline Step 1 & 0.161 & Gender ${ }^{*}$ & $F(1,48)=9.187, p=0.004$ & 0.401 & 3.031 & 0.004 \\
\hline \multicolumn{7}{|l|}{ Motor coordination } \\
\hline Step 1 & 0.156 & $\begin{array}{c}\text { Number of } \\
\text { hospitalization }\end{array}$ & $F(1,48)=8.849, p=0.005$ & 0.395 & 2.975 & 0.005 \\
\hline \multicolumn{7}{|c|}{ Sequencing of complex motor acts } \\
\hline Step 1 & 0.180 & Education (yrs) & $F(1,48)=10.541, p=0.002$ & -0.424 & -3.247 & 0.002 \\
\hline Other soft neurologic & & & & & & \\
\hline
\end{tabular}

${ }^{*}$ Gender: 0: Women, 1: Male, ${ }^{\S} \mathrm{All}$ independent variables are excluded from the stepwise regression model

Our findings suggested a correlation between general psychopathology and total NES, especially sensory integration. In general, negative symptoms were found to be the most relevant factors correlated with NSS (52-57), but motor signs were especially correlated with negative symptoms (58). Few studies have found significant associations with positive symptoms (59-61). While our study differs from other studies in terms of these results, a strong correlation between general symptoms of schizophrenia and NSS was reported in a meta-analysis (5). This notion has been confirmed by longitudinal studies addressing that the associations between psychotic symptomatology and NSS increase over time (4). In addition, differences in the strength of these associations may be a function of age, duration of the disease, and symptom severity in our outpatient group.

In healthy controls, anxiety and depression were correlated with the sequencing of complex motor acts, other NSS, and the total NES score. The presence of NSS is thought to help distinguish bipolar disorder from diseases that are less likely to have a neurodevelopmental component, such as unipolar depression (62-67). However, there are studies showing the presence of NSS in depression (65) and a correlation between NSS and anxiety-depressive symptomatology and childhood maltreatment (66).

Our study revealed a chronotype difference between patients with schizophrenia and healthy control participants and suggested an association with the eveningness chronotype in patients with schizophrenia, as was suggested in previous studies $(26,33,67,68)$.
However, no correlation was found between NSS and chronotype. The hypothesis that NSS and chronotype may have a relationship due to the common phenotypic characteristics was not confirmed in our study. Since our study is the first study on this relationship, this hypothesis can be tested in future studies.

On the other hand, relationships including impairment in sensory integration and poor subjective sleep quality, andimpairment in sensory integration and longer sleep latency were substantial in patients with schizophrenia. Sleep and circadian rhythm impairment in schizophrenia have been reported as hallmarks of the disorder $(69,70)$. Patients with schizophrenia have been reported to experience "a wide range of sleep disruption phenotypes" that may have substantial suggestions for understanding the underlying pathophysiology of the disorder (71). Difficulties with sleep continuity and increased sleep onset latency are also among these phenotypes (72-75), which are also observed in the prodromal phase $(67,68)$. The finding that deterioration in sensory integration is associated with sleep disturbance in our study also contributes to the hypothesis that disruption of sleep and atypical brain functioning may be interlaced (76). Similarly, the finding that deterioration in NSS was also associated with sleep-related parameters in healthy control participants in our study supports these notions. So much so that we found an association between NSS, especially difficulties in motor coordination and sleep disturbances and an association between the sequencing of complex motor acts and poor sleep quality in healthy controls. 
In addition, our study demonstrated impairments in sensory integration, the sequencing complex motor acts, and other NSS in patients with schizophrenia, even after adjusting for sociodemographic characteristics and other scale scores. The fact that NSS weresignificantly higher in patients even if other variables were fixed shows that NSS are a part of the persistent condition of the disease. In our study, we also found that NSS emerged with affective changes in healthy controls but were not influenced by affective changes in the patient group. These results indicate that NSS can be considered as a marker in schizophrenia. Evidence suggesting that deteriorations in neurodevelopmental processes are an important risk factor in schizophrenia is increasing (77-81). NSS were independently related to obstetric complications, genetic liability toschizophrenia, impairment in premorbid functioning, neurodevelopmental delay, and motor disorders (9). A study suggested a polygenic overlap between schizophrenia and NSS scores (82). Only a study that evaluated NSS in subjects without a family history of any mental disorders reported the presence of frequent silent neurodevelopmental deterioration in the general population and suggested that NSS are "possibly a weak generic rather than specific risk factor" (83).

Finally, our study showed that general psychopathology and lower levels of education were significantly correlated with NSS. In addition, lower levels of education were significantly associated with significant deterioration in the sequencing of complex motor acts. Unlike the general literature that suggests NSS are associated with negative symptoms, we found that general psychopathology predicts NSS. As we have previously discussed, this difference may be due to differences in variables such as age, duration of disease, and symptom severity in our outpatient group. However, most previous studies have also reported a negative relationship between NSS and education level $(52,57,84)$. In our study, male gender was significantly associated with impairment in sensory integration. The literature suggests NSS are more common and more permanent in men than in women; this difference may be due to the timing of brain maturation and higher birth complications in males (85-87). An association was also found between the number of hospitalizations and impairment in motor coordination. This finding may be associated with the duration and the severity of the disease, and it is also possible that neuroleptics may contribute to the emergence of NSS (88).
Some limitations of the present study should be considered while interpreting our results. First, our study was a cross-sectional study, and motor abnormalities may vary during the long-term follow-up of the disease. Second, the effect of the type and dose of antipsychotic were not clarified. In addition, the measurement of sleep disorders in this study was based solely on self-report questionnaires, without further objective evaluation, such as actigraphy or polysomnography. Finally, to date, although the NES has been instrumental in evaluating NSS in Turkish samples, psychometric properties of the Turkish version have not been addressed adequately.Psychometric features of the Turkish version should be warranted in further studies.

There are many studies investigating NSS in schizophrenia and investigating chronotypes in affective disorders, but our study is crucial in terms of the fact that the chronotype in schizophrenia is a less researched area and that it also evaluated NSS. We determined a relationship between sensory integration and sleep quality, yet we could not find any relationships between NSS and chronotype in our study. However, we did not have the opportunity to compare our results with similar studies, since we were unable to find any studies on this subject in the literature. Although the possible effect of chronotype on psychosis is not as clear as NSS, our data suggests a circadian disruption involvement in the sleep-wake phenotypes in patients with schizophrenia. To improve the prevention and treatment of related disorders, future research should demonstrate a mechanical connection and improve biological understanding by examining the possible antipsychotic drug effects on circadian rhythms and molecular processes underlying NSS in a longitudinal perspective.

\begin{tabular}{|c|c|c|}
\hline \multicolumn{2}{|c|}{ Contribution Categories } & \multirow{2}{*}{$\begin{array}{l}\text { Author Initials } \\
\text { E.E.K., M.B., M.G. }\end{array}$} \\
\hline \multirow{3}{*}{ Category 1} & Concept/Design & \\
\hline & Data acquisition & M.A., M.K., E.E.K. \\
\hline & Data analysis/Interpretation & E.E.K., M.B. \\
\hline \multirow{2}{*}{ Category 2} & Drafting manuscript & E.E.K., M.G. \\
\hline & Critical revision of manuscript & M.B., M.G. \\
\hline Category 3 & Final approval and accountability & E.E.K., M.B., M.G. \\
\hline \multirow{2}{*}{ Other } & Technical or material support & M.B. \\
\hline & Supervision & M.B., M.G. \\
\hline
\end{tabular}

Ethics Committee Approval: This study was approved by the Katip Celebi University Ethic Committee (Date: 10/10/2018, Number: 316).

Informed Consent: All participants gave written and informed consent to participate in accordance with the Declaration of Helsinki after the institutional review board approval. 
Peer-review: Externally peer-reviewed.

Conflict of Interest: The authors declare no conflict of interest.

Financial Disclosure: The authors declare that the current study was not financially supported by any institution or organization.

\section{REFERENCES}

1. Heinrichs DW, Buchanan RW. Significance and meaning of neurological signs in schizophrenia. Am J Psychiatry 1988; 145:11-18.

2. Tucker GJ, Silberfarb PM. Neurologic dysfunction in schizophrenia: significance for diagnostic practice: In Akiskal $\mathrm{H}$, Webb W, editors. Psychiatric Diagnosis: Exploration of Biological Predictors. New York: Spektrum, 1978, 453-462.

3. Boks MP, Russo S, Knegtering R, van den Bosch RJ. The specificity of neurological signs in schizophrenia: a review. Schizophr Res 2000; 43:109-116.

4. Bachmann S, Schröder J. Neurological Soft Signs in Schizophrenia: An Update on the State- versus Trait-Perspective. Front Psychiatry 2018; 8:272.

5. Chan RC, Xu T, Heinrichs RW, Yu Y, Wang Y. Neurological soft signs in schizophrenia: a meta-analysis. Schizophr Bull 2010; 36:1089-1104

6. Woods BT, Kinney DK, Yurgelun-Todd D. Neurologic abnormalities in schizophrenic patients and their families. I. Comparison of schizophrenic, bipolar, and substance abuse patients and normal controls. Arch Gen Psychiatry 1986; 43:657663.

7. Xu T, Wang Y, Li Z, Huang J, Lui SS, Tan SP, et al. Heritability and familiality of neurological soft signs: evidence from healthy twins, patients with schizophrenia and non-psychotic firstdegree relatives. Psychol Med 2016; 46:117-123.

8. Caldani S, Amado I, Bendjemaa N, Vialatte F, Mam-Lam-Fook C, Gaillard R, et al. Oculomotricity and Neurological Soft Signs: Can we refine the endophenotype? A study in subjects belonging to the spectrum of schizophrenia. Psychiatry Res 2017; 256:490497.

9. Peralta V, de Jalón EG, Campos MS, Basterra V, Sanchez-Torres A, Cuesta MJ. Risk factors, pre-morbid functioning and episode correlates of neurological soft signs in drug-naive patients with schizophrenia-spectrum disorders. Psychol Med 2011; 41:12791289.

10. Kolakowska T, Williams AO, Jambor K, Ardern M. Schizophrenia with good and poor outcome. III: Neurological 'soft' signs, cognitive impairment and their clinical significance. $\mathrm{Br}$ J Psychiatry 1985; 146:348-357.

11. Feng Y, Wang Z, Lin G, Qian H, Gao Z, Wang X, et al. Neurological soft signs and neurocognitive deficits in remitted patients with schizophrenia, their first-degree unaffected relatives, and healthy controls. Eur Arch Psychiatry Clin Neurosci 2020; 270:383-391.

12. Chan RC, Wang Y, Wang L, Chen EY, Manschreck TC, Li ZJ, et al. Neurological soft signs and their relationships to neurocognitive functions: a re-visit with the structural equation modeling design. PLoS One 2009; 4:e8469.
13. Cuesta MJ, Moreno-Izco L, Ribeiro M, López-Ilundain JM, Lecumberri P, Cabada T, et al. Motor abnormalities and cognitive impairment in first-episode psychosis patients, their unaffected siblings and healthy controls. Schizophr Res 2018; 200:50-55.

14. Lemmer B. Discoveries of rhythms in human biological functions: a historical review. Chronobiol Int 2009; 26:1019-1068.

15. Reinberg A, Ashkenazi I. Concepts in human biological rhythms. Dialogues Clin Neurosci 2003; 5:327-342.

16. Sahbaz C, Devetzioglou T, Ozcelik AM, Kirpinar I. Circadian preferences are associated with vegetative symptoms and comorbid medical diseases in patients with major depression. Biol Rhythm Research 2019; 50:703-717.

17. Adan A, Lachica J, Caci H, Natale V. Circadian typology and temperament and character personality dimensions. Chronobiol Int 2010; 27:181-193.

18. Emens JS, Yuhas K, Rough J, Kochar N, Peters D, Lewy AJ. Phase angle of entrainment in morning- and evening-types under naturalistic conditions. Chronobiol Int 2009; 26:474-493.

19. Gulec M, Selvi Y, Boysan M, Aydin A, Oral E, Aydin EF. Chronotype effects on general well-being and psychopathology levels in healthy young adults. Biological Rhythm Research 2013; 44:457-468.

20. Taillard J, Philip P, Bioulac B. Morningness/eveningness and the need for sleep. J Sleep Res 1999; 8:291-295.

21. Franzen PL, Buysse DJ. Sleep disturbances and depression: risk relationships for subsequent depression and therapeutic implications. Dialogues Clin Neurosci 2008; 10:473-481.

22. Selvi Y, Aydin A, Atli A, Boysan M, Selvi F, Besiroglu L. Chronotype differences in suicidal behavior and impulsivity among suicide attempters. Chronobiol Int 2011; 28:170-175.

23. Nutt D, Wilson S, Paterson L. Sleep disorders as core symptoms of depression. Dialogues Clin Neurosci 2008; 10:329-336.

24. Hasler BP, Allen JJ, Sbarra DA, Bootzin RR, Bernert RA. Morningness-eveningness and depression: preliminary evidence for the role of the behavioral activation system and positive affect. Psychiatry Res 2010; 176:166-173.

25. Yates NJ. Schizophrenia: the role of sleep and circadian rhythms in regulating dopamine and psychosis. Rev Neurosci 2016; 27:669-687.

26. Wulff K, Dijk DJ, Middleton B, Foster RG, Joyce EM. Sleep and circadian rhythm disruption in schizophrenia. Br J Psychiatry 2012; 200:308-316.

27. Lemoine P, Zawieja P, Ohayon MM. Associations between morningness/eveningness and psychopathology: an epidemiological survey in three in-patient psychiatric clinics. J Psychiatr Res 2013; 47:1095-1098.

28. Yu JH, Yun $\mathrm{CH}$, Ahn JH, Suh S, Cho HJ, Lee SK, et al. Evening chronotype is associated with metabolic disorders and body composition in middle-aged adults. J Clin Endocrinol Metab 2015; 100:1494-1502.

29. Torner C, Aguilar-Roblero R. Asynchrony in the diurnal rhythms of dopaminergic D2 receptors in different brain regions of the rat. Biol Rhythm Research 2010; 32:363-388. 
30. Dijk DJ, Archer SN. PERIOD3, circadian phenotypes, and sleep homeostasis. Sleep Med Rev 2010; 14:151-160.

31. Hampp G, Ripperger JA, Houben T, Schmutz I, Blex C, PerreauLenz S, et al. Regulation of monoamine oxidase A by circadianclock components implies clock influence on mood. Curr Biol 2008; 18:678-683.

32. Wulff K, Porcheret K, Cussans E, Foster RG. Sleep and circadian rhythm disturbances: multiple genes and multiple phenotypes. Curr Opin Genet Dev 2009; 19:237-246.

33. Lunsford-Avery JR, Gonçalves BDSB, Brietzke E, Bressan RA, Gadelha A, Auerbach RP, et al. Adolescents at clinical-high risk for psychosis: circadian rhythm disturbances predict worsened prognosis at 1-year follow-up. Schizophr Res 2017; 189:37-42.

34. Bromundt V, Köster M, Georgiev-Kill A, Opwis K, Wirz-Justice A, Stoppe G, et al. Sleep-wake cycles and cognitive functioning in schizophrenia. Br J Psychiatry 2011; 198:269-276.

35. First MB, Spitzer RL, Gibbon M, Williams JBW. Structured Clinical Interview for DSM-IV Clinical Version (SCID-I/CV) Washington DC: American Psychiatric Press, 1997.

36. Buchanan RW, Heinrichs DW. The Neurological Evaluation Scale (NES): a structured instrument for the assessment of neurological signs in schizophrenia. Psychiatry Res 1989; 27:335-350.

37. Tapancı Z, Ylldırım A, Boysan M. Neurological soft signs, dissociation and alexithymia in patients with obsessivecompulsive disorder (OCD) and healthy subjects. Psychiatry Res 2018; 260:90-97.

38. Kay SR, Fiszbein A, Opler LA. The positive and negative syndrome scale (PANSS) for schizophrenia. Schizophr Bull 1987; 13(2):261-276.

39. Kostakoglu AE, Batur S, Tiryaki AG, Gogus A. Validity and reliability of the Turkish adaptation of the Positive and Negative Syndrome Scale (PANSS). Türk Psikiyatri Derg 1999; 14:23-32.

40. Horne JA, Ostberg O. A self-assessment questionnaire to determine morningness-eveningness in human circadian rhythms. Int J Chronobiol 1976; 4:97-110.

41. Agargun MY, Cilli AS, Boysan M, Selvi Y, Gulec M, Kara H. Turkish Version of Morningness Eveningness Questionnaire (MEQ). Sleep and Hypnosis 2007; 9:16-23.

42. Buysse DJ, Reynolds CF 3rd, Monk TH, Berman SR, Kupfer DJ. The Pittsburgh Sleep Quality Index: a new instrument for psychiatric practice and research. Psychiatry Res 1989; 28:193-213.

43. Agargun MY, Kara H, Anlar O. The validity and reliability of the Pittsburgh Sleep Quality Index. Turk Psikiyatri Derg 1996; 7:107111.

44. Beck AT, Ward CH, Mendelson M, Mock J, Erbaugh J. An inventory for measuring depression. Arch Gen Psychiatry 1961; 4:561-571.

45. Hisli N. Beck A reliability and validity study of Beck Depression Inventory in a university student sample. Journal of Psychology. 1989; 7:3-13.

46. Beck AT, Epstein N, Brown G, Steer RA. An inventory for measuring clinical anxiety: psychometric properties. J Consult Clin Psychol 1988; 56:893-897.
47. Ulusoy M, Sahin N, Erkmen H. Turkish version of the Beck Anxiety Inventory: psychometric properties. Journal of Cognitive Psychotherapy 1998; 12:163- 172.

48. Selvi Y, Aydin A, Boysan M, Atli A, Agargun MY, Besiroglu L. Associations between chronotype, sleep quality, suicidality, and depressive symptoms in patients with major depression and healthy controls. Chronobiol Int 2010; 27:1813-1828.

49. Selvi Y, Boysan M, Kandeger A, Uygur OF, Sayin AA, Akbaba $\mathrm{N}$, et al. Heterogeneity of sleep quality in relation to circadian preferences and depressive symptomatology among major depressive patients. J Affect Disord 2015; 235:242-249.

50. Ramsawh HJ, Stein MB, Belik SL, Jacobi F, Sareen J. Relationship of anxiety disorders, sleep quality, and functional impairment in a community sample. J Psychiatr Res 2009; 43:926-933.

51. Antypa N, Vogelzangs N, Meesters Y, Schoevers R, Penninx BW. Chronotype associations with depression and anxiety disorders in a large cohort study. Depress Anxiety 2016; 33:75-83.

52. Whitty P, Clarke M, Browne S, McTigue O, Kamali M, Feeney L, et al. Prospective evaluation of neurological soft signs in first-episode schizophrenia in relation to psychopathology: state versus trait phenomena. Psychol Med 2003; 33:1479-1484.

53. Chan RCK, Geng FL, Lui SSY, Wang Y, Ho KKY, Hung KSY, et al. Course of neurological soft signs in first-episode schizophrenia: Relationship with negative symptoms and cognitive performances. Sci Rep 2015; 5:11053.

54. Emsley R, Chiliza B, Asmal L, Kilian S, Riaan Olivier M, Phahladira L, et al. Neurological soft signs in first-episode schizophrenia: State- and trait-related relationships to psychopathology, cognition and antipsychotic medication effects. Schizophr Res 2017; 188:144-150.

55. Prikryl R, Ceskova E, Kasparek T, Kucerova H. Neurological soft signs, clinical symptoms and treatment reactivity in patients suffering from first episode schizophrenia. J Psychiatr Res 2006; 40:141-146.

56. Schröder J, Silvestri S, Bubeck B, Karr M, Demisch S, Scherrer S, et al. D2 dopamine receptor up-regulation, treatment response, neurological soft signs, and extrapyramidal side effects in schizophrenia: a follow-up study with 123I-iodobenzamide single photon emission computed tomography in the drugnaive state and after neuroleptic treatment. Biol Psychiatry 1998;43:660-665.

57. Whitty P, Clarke M, McTigue O, Browne S, Gervin M, Kamali M, et al. Diagnostic specificity and predictors of neurological soft signs in schizophrenia, bipolar disorder and other psychoses over the first 4 years of illness. Schizophr Res 2006; 86:110-117.

58. Chen EY, Hui CL, Chan RC, Dunn EL, Miao MY, Yeung WS, et al. A 3-year prospective study of neurological soft signs in firstepisode schizophrenia. Schizophr Res 2005; 75:45-54.

59. Mangot AG, Sawant NS. First episode schizophrenia: neurological abnormalities and prognosis. German J Psychiatry 2013; 16:7580.

60. Mittal VA, Hasenkamp W, Sanfilipo M, Wieland S, Angrist B, Rotrosen J, et al. Relation of neurological soft signs to psychiatric symptoms in schizophrenia. Schizophr Res 2007; 94:37-44. 
61. Herold CJ, Lässer MM, Seidl UW, Hirjak D, Thomann PA, Schröder J. Neurological soft signs and psychopathology in chronic schizophrenia: a cross-sectional study in three age groups. Front Psychiatry 2018; 9:98.

62. Sagheer TA, Assaad S, Haddad G, Hachem D, Haddad C, Hallit S. Neurological soft signs in bipolar and unipolar disorder: A casecontrol study. Psychiatry Res 2018; 261:253-258.

63. Zhao Q, Ma YT, Lui SS, Liu WH, Xu T, Yu X, et al. Neurological soft signs discriminate schizophrenia from major depression but not bipolar disorder. Prog Neuropsychopharmacol Biol Psychiatry 2013; 43:72-78.

64. Shaffer D, Schonfeld I, O'Connor PA, Stokman C, Trautman P, Shafer S, et al. Neurological soft signs. Their relationship to psychiatric disorder and intelligence in childhood and adolescence. Arch Gen Psychiatry 1985; 42:342-351.

65. Livianos L, González-Valls PI, García-Blanco AC, Tobella H, Díaz-Alonso I, Alberola N, et al. Hypoesthesia of the malleolus as a soft sign in depression. J Affect Disord 2015; 171:128-131.

66. Zhao H, Guo W, Niu W, Zhong A, Zhou X. Brain area-related neurological soft signs in depressive patients with different types of childhood maltreatment. Asia Pac Psychiatry 2015; 7:286-291.

67. Castro J, Zanini M, Gonçalves Bda S, Coelho FM, Bressan R, Bittencourt $\mathrm{L}$, et al. Circadian rest-activity rhythm in individuals at risk for psychosis and bipolar disorder. Schizophr Res 2015; 168:50-55

68. Zanini M, Castro J, Coelho FM, Bittencourt L, Bressan RA, Tufik S, et al. Do sleep abnormalities and misaligned sleep/ circadian rhythm patterns represent early clinical characteristics for developing psychosis in high risk populations? Neurosci Biobehav Rev 2013; 37:2631-2637.

69. Cohrs S. Sleep disturbances in patients with schizophrenia: impact and effect of antipsychotics. CNS Drugs 2008; 22:939962.

70. Krysta K, Krzystanek M, Bratek A, Krupka-Matuszczyk I. Sleep and inflammatory markers in different psychiatric disorders. J Neural Transm (Vienna) 2017; 124(Suppl.1):179-186.

71. Wulff K, Gatti S, Wettstein JG, Foster RG. Sleep and circadian rhythm disruption in psychiatric and neurodegenerative disease. Nat Rev Neurosci 2010; 11:589-599.

72. Benson KL. Sleep in schizophrenia: impairments, correlates, and treatment. Psychiatr Clin North Am 2006; 29:1033-1045.

73. Tandon R, Nasrallah HA, Keshavan MS. Schizophrenia, "just the facts" 4. Clinical features and conceptualization. Schizophr Res 2009; 110:1-23.

74. Waters F, Manoach DS. Sleep dysfunctions in schizophrenia: a practical review. Open Journal of Psychiatry 2012; 2:384-392.

75. Kilicaslan EE, Esen AT, Kasal MI, Ozelci E, Boysan M, Gulec M. Childhood trauma, depression, and sleep quality and their association with psychotic symptoms and suicidality in schizophrenia. Psychiatry Res 2017; 258:557-564.

76. Cosgrave J, Wulff K, Gehrman P. Sleep, circadian rhythms, and schizophrenia: where we are and where we need to go. Curr Opin Psychiatry 2018; 31:176-182.

77. Tamagni C, Studerus E, Gschwandtner U, Aston J, Borgwardt S, Riecher-Rössler A. Are neurological soft signs pre-existing markers in individuals with an at-risk mental state for psychosis? Psychiatry Res 2013; 210:427-431.

78. Gay O, Plaze M, Oppenheim C, Mouchet-Mages S, Gaillard R, Olie JP, et al. Cortex morphology in first-episode psychosis patients with neurological soft signs. Schizophr Bull 2013; 39:820-829.

79. Gourion D, Goldberger C, Olie JP, Lôo H, Krebs MO. Neurological and morphological anomalies and the genetic liability to schizophrenia: a composite phenotype. Schizophr Res 2004; 67:23-31.

80. Compton MT, Bollini AM, McKenzie Mack L, Kryda AD, Rutland J, Weiss PS, et al. Neurological soft signs and minor physical anomalies in patients with schizophrenia and related disorders, their first-degree biological relatives, and nonpsychiatric controls. Schizophr Res 2007; 94:64-73.

81. Dazzan P, Murray RM. Neurological soft signs in first-episode psychosis: a systematic review. Br J Psychiatry Suppl 2002; 43:s50-57.

82. Srinivasan S, Bettella F, Mattingsdal M, Wang Y, Witoelar A, Schork AJ, et al. Genetic Markers of Human Evolution Are Enriched in Schizophrenia. Biol Psychiatry 2016; 80:284-292.

83. Fountoulakis KN, Panagiotidis P, Kimiskidis V, Nimatoudis I, Gonda X. Prevalence and correlates of neurological soft signs in healthy controls without family history of any mental disorder: A neurodevelopmental variation rather than a specific risk factor? Int J Dev Neurosci 2018; 68:59-65.

84. Chen EY, Kwok CL, Au JW, Chen RY, Lau BS. Progressive deterioration of soft neurological signs in chronic schizophrenic patients. Acta Psychiatr Scand 2000; 102:342-349.

85. Alamiri B, Nelson C, Fitzmaurice GM, Murphy JM, Gilman SE. Neurological soft signs and cognitive performance in early childhood. Dev Psychol 2018; 54:2043-2052.

86. Cai L, Zhu X, Yi J, Bai M, Wang M, Wang Y, et al. Neurological soft signs and their relationship with measures of executive function in Chinese adolescents. J Dev Behav Pediatr 2013; 34:197-203.

87. Martins I, Lauterbach M, Slade P, Luís H, DeRouen T, Martin $\mathrm{M}$, et al. A longitudinal study of neurological soft signs from late childhood into early adulthood. Dev Med Child Neurol 2008; 50:602-607.

88. Gupta S, Andreasen NC, Arndt S, Flaum M, Schultz SK, Hubbard WC, et al. Neurological soft signs in neuroleptic-naive and neuroleptic-treated schizophrenic patients and in normal comparison subjects. Am J Psychiatry 1995; 152:191-196. 